\title{
Triangular relationship among risky sexual behavior, addiction, and aggression: A systematic review
}

\author{
Khodabakhsh Ahmadi ${ }^{1}$, Seyed Alireza Javadinia ${ }^{2}$, Seyed Hassan Saadat ${ }^{3}$, Mohammad Arash Ramezani ${ }^{4}$, Homa \\ Sedghijalal ${ }^{5}$
}

${ }^{1}$ Ph.D. in Counseling Psychology, Associate Professor, Behavioral Sciences Research Center, Baqiyatallah University of Medical Sciences, Tehran, Iran

${ }^{2}$ Resident of Radiation Oncology, Student Research Committee, Mashhad University of Medical Sciences, Mashhad, Iran

${ }^{3}$ M.D., Behavioral Sciences Research Center, Baqiyatallah University of Medical Sciences, Tehran, Iran

${ }^{4}$ Ph.D., Associate Professor, Behavioral Sciences Research Center, Baqiyatallah University of Medical Sciences, Tehran, Iran

${ }^{5}$ Ph.D., Behavioral Sciences Research Center, Baqiyatallah University of Medical Sciences, Tehran, Iran

Type of article: Systematic review

\begin{abstract}
Background: Risky sexual behavior (RSB), addiction, and aggression are three important personal and social factors which influence each other.

Objective: To overview the potential relationship among RSB, addiction, and aggression to conduct an interactive model for the pathology and management of human behavior.

Methods: This review article was carried out by searching studies in PubMed, Medline, Web of Science, Ebsco, IEEE, Scopus, Springer, MagIran, and IranMedex databases from the year 1993 to 2013. The search terms were violence, aggression, drug abuse, substance abuse, illicit drug, psychoactive drug, intravenous drug users, addiction and high-risk sexual relationships, unprotected sex, high risk sexual behavior, and sexual risk-taking. In this study, forty-nine studies were accepted for further screening, and met all our inclusion criteria (in English or Persian, full text, and included the search terms).

Results: Forty-nine articles were included; 17 out of 26 studies showed a significant correlation between addiction and risky sexual behavior, 15 out of 19 articles indicated a statistically significant correlation between aggression and addiction, and 9 out of 10 articles reported significant correlation between aggression and risky sexual behavior.

Conclusion: According to the results, the triangle hypothesis of sex, addiction, and aggression led to the definition of the relationship among the variables of the hypothetical triangle based on the reviewed studies; and the proposed dual and triple relationship based on the conducted literature review was confirmed. This is not a meta-analysis, and there is no analysis of publication bias.
\end{abstract}

Keywords: High Risk Sex, Unprotected Sex, Addictive Behavior, Aggression

\section{Introduction}

High-risk behavior such as aggression, substance abuse, and risky sexual behavior (RSB) could be associated with increased anxiety in adolescents, and increased probability of depression, suicide (1), poisoning, alcoholism irritability (2), unprotected sex, having multi-sex partners, exposure to sexually transmitted diseases, and involvement in physical fighting and its consequent injuries $(3,4)$. RSB includes any unprotected sex with an unknown person (promiscuity or nonuse of condoms, which are considered as risk factors for sexually transmitted diseases), and/or frequently changing sexual partners, which influence the health status of society and cause social problems $(5,6)$. People with RSB, in many cases also deal with other behavioral disorders such as addiction, as Gilchrist et al. reported, substance abuse is highly frequent before attempting to high-risk sexual behavior ( $\beta=0.163$,

\section{Corresponding author:}

Dr. Seyed Alireza Javadinia, Department of Radiation Oncology, Faculty of Medicine, Mashhad University of Medical Sciences, Mashhad, Iran. Tel: +985138426936, Email: javadinia.alireza@gmail.com

Received: February 21, 2017, Accepted: April 28, 2017, Published: August 2017

iThenticate screening: April 28, 2017, English editing: July 12, 2017, Quality control: August 02, 2017

(C) 2017 The Authors. This is an open access article under the terms of the Creative Commons Attribution-NonCommercialNoDerivs License, which permits use and distribution in any medium, provided the original work is properly cited, the use is non-commercial and no modifications or adaptations are made. 
$\mathrm{p}<0.01)$ (7). Also, Rusch et al. reported that risk of unprotected anal sex increased with substance abuse (OR=1.64) (8). Substance abuse disorders can be associated with impulsive behavior, which plays an important role in several key transition phases of drug abuse (9), and operating independently with sexual risk-taking behavior (10). People who engage in RSB, also, express themselves more with aggressive behavior. Mustanski et al reported that physical violence increased with the likelihood of having unprotected sex $\mathrm{OR}=1.88$ (1.13-3.13) (11). Aggressive behavior is defined as behavior that can cause physical or emotional harm to others such as verbal abuse, physical abuse, and sexual abuse, or can also involve harming personal property (12). Drug addiction is a mental disease affected by several biological, developmental, and social factors, which has a strong spiritual component and societal views on it, rooted in spiritual/religious perspectives (13). Drug abuse can induce neuroplasticity in brain reward circuits, memory, self-control, and stress processing, which are critically involved in the aforementioned impulsive behaviors (14). Also, most addicts display violent behavior in the absence of drugs, and in the withdrawal phase $(15,16)$. Ahmadi et al reported that addiction of spouse is significantly associated with domestic violence against women $(\mathrm{OR}=2.8)$ (17). Triangular models (interactive models) as a public health model of primary care was presented in 2002 by Sulmasy. He stated: "Rather, in this biopsychosocial-spiritual model, the biological, psychological, social, and spiritual aspects are only the distinct dimensions of the person, and no aspect alone can be disaggregated from the whole. Each aspect can be affected differently by a person's history and illness, and each aspect can interact and affect other aspects of the person" (18). Based on our literature review, there were no previous articles which directly described a triangular model for RSB, addiction, and aggression. However, Mirsoleimani et al. (19), Zinat Motlagh et al. (20), Tucker et al. (21), and Mustanski et al. (11) reported the positive relationship between sexual behaviors, addiction, and aggression. Probably, according to the possible existence of this triangular relationship, preventing and controlling each of the studied variables could prevent or reduce the expression of other variables; the need for and the importance of these containments is clearly demonstrated. This review is aimed to overview the potential relationship among RSB, addiction, and aggression, to conduct an interactive model for the pathology and management of human behavior.

\section{Material and Methods}

This review article was carried out by searching studies in PubMed, Medline, Web of Science, Ebsco, IEEE, Scopus, Springer, MagIran, and IranMedex databases from the year 1993 to 2013. In addition, hand-searching of key journals, references of the selected articles in both English and Persian, and gray literature were investigated. Animal studies were not included in the present review. To ensure that no relevant papers are lost, the lists of review articles were also fully investigated. The key words used for the search were [Violence OR Aggression] AND ["drug abuse" OR "substance abuse" OR "illicit drug" OR "psychoactive drug" OR Injection OR "intravenous drug users" OR addiction] AND ["high-risk sexual relationships" OR "unprotected sex" OR high risk sexual behavior" OR "sexual risk-taking"]. The search strategy was modified and customized for every database. Inclusion criteria were the aforementioned key words used to search for the relevant articles published from 1993 to 2013, their full text should be available in English or Persian. Exclusion criteria were when only abstract was available and articles not in the timeline of study. Those articles not matching our inclusion criteria (in other languages than English, between the timeline of study) were excluded from the study. The present study employed the STROBE (strengthening the reporting of observational studies in epidemiology) for the quality assessment of the included articles.

\section{Results}

A total of 5,431 articles were found by searching the databases. After eliminating the duplicate articles and reviewing the titles and abstracts, 3,019 articles were selected for the current review. After removing 2,433 unrelated records, 586 full texts were assessed for eligibility. After reading the full text of the articles, according to the inclusion and exclusion criteria mentioned in the methodology, a total of 49 articles were evaluated, of which 26 studied the relationship between addiction and RSB, 19 articles studied the relationship between aggression and addiction, and finally, 10 of them studied aggression and RSB. Out of 26 studies, 17 showed a significant correlation between addiction (substance abuse) and RSB and 1 article reported the absence of such a relationship. Eight remaining articles either did not mention such a relationship, or did not use suitable statistical analysis methods and merely addressed descriptive issues. In the examination of the relationship between aggression and addiction, 15 of 19 articles showed a statistically significant correlation; 1 article did not find any correlations, and 3 articles either did not find any relationships or merely had a descriptive purpose (not analytical). A total of 10 articles examined the relationship between aggression and RSBs, 9 of them reported significant correlation between these 2 variables, and 2 articles only, discussed the subject disruptively. Among the studied articles, a more limited number of articles (4) had studied and discussed all 3 variables (Tables 1-4). 
Table 1. List of reviewed articles on the relationship between sexual behaviors and addiction

\begin{tabular}{|c|c|c|}
\hline $\begin{array}{l}\text { Ref. } \\
\text { No. }\end{array}$ & Sample & Conclusion \\
\hline 8 & Homosexual males $(\mathrm{n}=261)$ & $\begin{array}{l}\text { Drug abuse during or before sex was significantly correlated with likelihood of } \\
\text { unprotected anal sex. }\end{array}$ \\
\hline 24 & $\begin{array}{l}\text { Residents of suburban areas } \\
(\mathrm{n}=400)\end{array}$ & Illicit sexual relations were common among IDUs and were commonly reported. \\
\hline 7 & Female students $(n=235)$ & There was a relationship between alcohol consumption by females and RSB. \\
\hline 27 & Homeless youths $(\mathrm{n}=309)$ & $\begin{array}{l}\text { Lower likelihood of using a condom during sex was significantly associated with } \\
\text { heavy consumption of substances before an intimate relation. }\end{array}$ \\
\hline 11 & $\begin{array}{l}\text { Young homosexual men } \\
(\mathrm{n}=122)\end{array}$ & $\begin{array}{l}\text { Drug use before sex was significantly associated with an increased risk of unprotected } \\
\text { sex. }\end{array}$ \\
\hline 5 & $\begin{array}{l}\text { Consumers and non- } \\
\text { consumers of MET, mAMP }\end{array}$ & $\begin{array}{l}\text { There was a significant relationship between using MET, mAMP, US, and high-risk } \\
\text { sexual behaviors among drug users. The use of non-injecting MET, mAMP during sex } \\
\text { was correlated with RSB. }\end{array}$ \\
\hline 29 & $\begin{array}{l}\text { Females with a history of } \\
\text { alcohol consumption }(n=230)\end{array}$ & $\begin{array}{l}\text { There was an interaction between drunkenness and a common demand for unprotected } \\
\text { sex among females when facing high-risk sexual partner. }\end{array}$ \\
\hline 62 & IDUs $(n=246)$ & Being IDU was correlated with US and multi-partner sexual relation. \\
\hline 30 & $\begin{array}{l}\text { HIV- homosexual males } \\
(\mathrm{n}=4295)\end{array}$ & $\begin{array}{l}\text { Abuse of alcohol, popper, MET, mAMP, and cocaine before or during sex } \\
\text { independently associated with unprotected anal sex. }\end{array}$ \\
\hline 31 & Homosexual HIV+ $(n=456)$ & $\begin{array}{l}\text { Multi-drugs abusers were at elevated risk of US (same/multiple partner). Alcohol } \\
\text { consumption in dominant males and poppers abuse in recipient males predicts } \\
\text { unprotected anal sex. }\end{array}$ \\
\hline 32 & $\begin{array}{l}\text { Drug abuse and RSB in } \\
\text { homosexual males }\end{array}$ & $\begin{array}{l}\text { Homosexual males were at greater risk of RSB, which increases the risk of using any } \\
\text { substances. }\end{array}$ \\
\hline 19 & Substances abusers $(\mathrm{n}=265)$ & Cocaine and MET, mAMP abusers had more tendencies toward RSB. \\
\hline 33 & Addicts $(n=796)$ & IDUs had multiple sexual partners, and showed more RSB. \\
\hline 56 & $\begin{array}{l}\text { MET, mAMP }(n=40) \text { and } \\
\text { narcotic abusers }(n=40)\end{array}$ & MET, mAMP use resulted in increased risk of unprotected sex with prostitutes. \\
\hline 63 & IDU men $(n=1510)$ & $\begin{array}{l}\text { IDUs had a history of illicit sexual relations mostly in the fashion of unprotected or } \\
\text { multi-partner relations. }\end{array}$ \\
\hline 21 & Poor females $(n=290)$ & The higher frequency of US was associated with drug abuse of both partners. \\
\hline
\end{tabular}

IDUs, injecting drug users; MET, mAMP, methamphetamine; RSB, risky sexual behavior, US, unprotected sex

Table 2. Literature that reported the positive relationship between aggression and drug addiction

\begin{tabular}{|c|c|c|}
\hline $\begin{array}{l}\text { Ref. } \\
\text { No. }\end{array}$ & Sample & Conclusion \\
\hline 17 & Married females $(\mathrm{n}=1189)$ & $\begin{array}{l}\text { There was a significant correlation between addiction and domestic violence against } \\
\text { females. }\end{array}$ \\
\hline 37 & $\begin{array}{l}\text { All self-sustaining females } \\
(\mathrm{n}=600)\end{array}$ & $\begin{array}{l}\text { There was a significant relationship between physical violence and addiction of a } \\
\text { spouse. }\end{array}$ \\
\hline 26 & $\begin{array}{l}12 \text { to } 17 \text {-year-old } \\
\text { adolescents }(n=4023)\end{array}$ & $\begin{array}{l}\text { Adolescents physically or sexually abused or witnessing violence and those who had } \\
\text { family members with substance or alcohol use had a higher risk for } \\
\text { dependency/substance abuse. }\end{array}$ \\
\hline 38 & Married females $(\mathrm{n}=460)$ & Addiction affected domestic violence against females. \\
\hline 39 & Married females $(n=400)$ & $\begin{array}{l}\text { Domestic violence against females had a significant correlation with addiction of males } \\
\text { and females. }\end{array}$ \\
\hline 44 & $\begin{array}{l}\text { Males with alcohol } \\
\text { addiction }(\mathrm{n}=124)\end{array}$ & Alcohol had a significant relationship with desires and feelings for violence. \\
\hline 7 & Prostitutes $(\mathrm{n}=113)$ & $\begin{array}{l}\text { Injecting heroin/smoking crack was correlated with physical or sexual violence in such } \\
\text { females. }\end{array}$ \\
\hline 46 & $\begin{array}{l}\text { Uninsured patients ( } 359 \\
\text { males and } 111 \text { females) }\end{array}$ & Physical and sexual abuse had a significant correlation with higher substance abuse. \\
\hline 47 & Adolescents $(\mathrm{n}=517)$ & $\begin{array}{l}\text { There was aggressive and maladaptive behavior correlated with the prevalence of } \\
\text { substance use. }\end{array}$ \\
\hline 19 & $\begin{array}{l}\text { Narcotics/drug abusers } \\
(\mathrm{n}=265)\end{array}$ & Crack abusers showed more aggressive behavior. \\
\hline 20 & Adolescents $(n=203)$ & $\begin{array}{l}\text { There was a significant correlation between smoking, alcohol, and drug abuse and } \\
\text { aggression of adolescents. }\end{array}$ \\
\hline 45 & $\begin{array}{l}\text { High school students } \\
(\mathrm{n}=3764)\end{array}$ & Drug abusers had a significant correlation with violent behavior and suicide. \\
\hline
\end{tabular}


Table 3. Studies that reviewed the positive relationship between violence and sexual behaviors

\begin{tabular}{|c|c|c|}
\hline $\begin{array}{l}\text { Ref. } \\
\text { No. }\end{array}$ & Sample & Conclusion \\
\hline 11 & Young homosexual males $(\mathrm{n}=122)$ & $\begin{array}{l}\text { Physical violence had a significant correlation with the } \\
\text { likelihood of having unprotected sex. }\end{array}$ \\
\hline 48 & $\begin{array}{l}\text { Non-homosexual unmarried males, ranged } 18 \text { to } 35 \\
\text { years }(n=289)\end{array}$ & $\begin{array}{l}\text { Significant association between risky sexual behavior, } \\
\text { violence, and sexual abuse in males. }\end{array}$ \\
\hline 49 & $\mathrm{HIV}+$ patients $(\mathrm{n}=100)$ & In people with RSBs, violence was higher. \\
\hline 50 & $\begin{array}{l}\text { People who wanted to be tested for HIV ( } 62 \\
\text { individuals with high-risk and } 32 \text { individuals with } \\
\text { low-risk sexual behaviors, and } 107 \text { normal } \\
\text { individuals) }\end{array}$ & In people with high-risk sexual behaviors, violence was higher. \\
\hline 64 & Female sex worker $(n=144)$ & $\begin{array}{l}\text { Female sex workers stated that they had experienced violence } \\
\text { from their own family and there was no intimacy between } \\
\text { family members. }\end{array}$ \\
\hline 44 & Non-homosexual unmarried males $(\mathrm{n}=289)$ & $\begin{array}{l}\text { Attitude toward females, failure in consistent use of condoms, } \\
\text { and number of sexual partners had a direct and significant } \\
\text { correlation with the behavior of males in their use of violence. }\end{array}$ \\
\hline 20 & Adolescents $(\mathrm{n}=203)$ & $\begin{array}{l}\text { There was a statistically significant relationship between high- } \\
\text { risk sexual behavior and aggression. }\end{array}$ \\
\hline 21 & Poor females without a permanent partner $(\mathrm{n}=290)$ & $\begin{array}{l}\text { The higher frequency of unprotected sex was significantly } \\
\text { correlated with psychological, physical, and sexual aggression. }\end{array}$ \\
\hline
\end{tabular}

Table 4. Articles that reported the positive relationship between sexual behaviors, addiction, and aggression.

\begin{tabular}{|l|l|l|}
\hline $\begin{array}{l}\text { Ref. } \\
\text { No. }\end{array}$ & Sample & Conclusion \\
\hline 19 & $\begin{array}{l}\text { Narcotics and drug } \\
\text { abusers }(\mathrm{n}=265)\end{array}$ & $\begin{array}{l}\text { The sexual behavior of cocaine abusers was at the highest level, and in crack users, was at the } \\
\text { lowest. The rate of high-risk sexual behaviors in cocaine and MET, mAMP abusers was higher } \\
\text { than those of the opium, heroin, and crack abusers, and the degree of self-harm was higher in } \\
\text { crack abusers compared to those of opium and MET, mAMP users. }\end{array}$ \\
\hline 20 & Adolescents $(\mathrm{n}=203)$ & $\begin{array}{l}\text { There was a statistically significant correlation between tobacco, alcohol, and drugs abuse and } \\
\text { high-risk sexual behaviors and aggression. }\end{array}$ \\
\hline 21 & $\begin{array}{l}\text { Poor females without } \\
\text { a permanent partner } \\
\text { (n=290) }\end{array}$ & $\begin{array}{l}\text { Higher frequency of unprotected sex was associated with substance abuse by partner, } \\
\text { psychological abuse and all forms of physical or sexual abuse, no request from sexual partners } \\
\text { to use condoms, less certain to reject unwanted sex, and less spontaneity to use condoms. }\end{array}$ \\
\hline 11 & $\begin{array}{l}\text { Young homosexual } \\
\text { males }(\mathrm{n}=122)\end{array}$ & $\begin{array}{l}\text { Drug abuse before sex, forced intimacy and physical violence was significantly associated with } \\
\text { an increased risk of unprotected sex. }\end{array}$ \\
\hline
\end{tabular}

MET, mAMP, methamphetamine

\section{Discussion}

In general, the results of the studies on the relationship between sexual behaviors and addiction were almost in one direction and the relationship between addiction and RSB was clearly shown in the studies by Mayer et al. (22), Leigh et al. (23), Razzaghi et al. (24), Rehm et al. (25), Kilpatric et al. (26), Gilchrist et al. (7), Tucker et al. (21,27), Rush et al. (8), Molitor et al. (5), Kane et al. (28), Podrie et al. (29), Colfax et al. (30), Porsel et al. (31), and Heath et al. (32). Assari et al., also showed that many people with intravenous substance abuse disorders had multiple sex partners, and high-risk sexual behaviors (33). Based on these studies, drug abuse or addiction increases the likelihood of high-risk sexual behavior (such as not using a condom, multiple sex partners, and engaging in anal sex particularly in homosexual males). In these studies, high-risk sexual behavior was often associated with drug abuse and alcohol consumption before or during high-risk sex. Unprotected and illicit sex was also the underlying trend for using drugs affected by the addiction of the person to drugs. In most studies conducted in this area, results showed that RSB was significantly common among drug users $(34,35)$. Also, Assari et al., clearly showed an association between high-risk sexual behavior and addiction (16). Although some studies suggested that high levels of income were associated with addiction to drugs, the general consensus insists on the opposite idea (36). It is noteworthy that a study on the cause and effect relationship on the tendency toward high-risk sexual behaviors and drug addiction was not observed. But some studies mentioned the likelihood of tendency of individuals with high-risk sexual behavior toward consumption of drugs and alcohol, which, according to the result of these observations, bilateral relationship hypothesis between the 2 variables seems not far-fetched. Researchers in the majority of studies to determine the relationship between addiction and violence (aggression), pay attention to physical, sexual, verbal, and psychological violence against females and substance abuse. Studies showed that aggression disorder is 
associated with using substances such as drugs, alcohol, and hallucinogens, and it can be observed as the increase of domestic violence among the wives of addicts $(17,20,37)$. In general, with a review of articles that paid attention to the relationship between these two variables, it was found that addiction (drug and alcohol abuse) and aggressive behavior had a significant and positive correlation. This relationship can also be examined from a different angle. In this sense, violence and aggressive behavior in an individual himself and/or among his family members and those around him, increases the likelihood of drug abuse. The studies by Ahmadi et al. (17), Saberian et al.(37), Derakhshanpour et al. (38), Balali Meybodi et al. (39), Fazel et al. (40), Tatari et al. (41), Zinat Motlagh (20), Abbey (42), Kilpatric et al. (43), Davis (44), Gilchrist et al. (7), Meyer et al. (22), Garrison et al. (45), Liebschutz et al. (46), and Epstein et al. (47) were among the studies that showed this correlation clearly (of either or both angles). Therefore, by relying on these articles, the bilateral relationship hypothesis between these two variables can be accepted. Also, in different studies, researchers could find a correlation between violence and RSB. This association may be bidirectional. Regarding the relationship between unprotected sex and use of violence, different studies showed that people with high-risk sexual behavior have significantly, more than other people, had the personality trait of neuroticism associated with emotional instability and extreme biological reactivity. On the other hand, when people are subjected to violence, it may result in RSB or engagement in it by violence. For example, forcing females or males into RSBs is often accompanied by violence; Davis et al. (48), Mustanski (11), Bayrami et al. (49), Abdi et al. (50), Zinat Motlagh et al. (20), Lescano et al. (51), Malamute et al. (52), and Tucker et al., intimated the same idea (21). Indeed, in the study by Rezazade et al., on the environmental impacts of these people, it was shown that staff in harm reduction centers that were in contact with these people, reported that they had mental disorders such as depression or insomnia, and this caused them to show aggressive behavior $(53,54)$. Only a limited number of studies examined and investigated all 3 variables discussed in the current review; of course, they had not mentioned the triangular relationship. Misoleimani et al. (19), Tucker et al. (21), Mustanski et al. (11), and Zina Motlagh et al. (20) had worked on all three variables and found significant relationships between addiction, aggression, and highrisk sexual behavior and had shown them in pairs of two. The idea of the triangle was the term that unified the concepts into a single theory. When emotional crises in a two-person system overpass a certain level, it "triangles" a third person (triangle as the smallest stable building block), and permits the tension to shift within the triangles. In fact, as long as tension and anxiety level is low, the system is stable. The emotional forces within triangles are consistently in motion instantly. Over a long period of time, a triangle relationship has long term postures and functioning positions and a triangle relationship can stabilize or destabilize a two-person system (55). By reviewing the previously mentioned literature, and conclusions from the general content of the majority of the researchers listed above, the dual interaction between RSB and violence, between addiction and RSB, and between addiction and aggression were observed. It may seem that addicts (drug and alcohol abusers), based on their behavioral and personality characteristics, engage in high-risk sexual practices; however, some researchers including Vaziri and Lotfi Kashani mentioned the effects of drugs on sexual drive and desire and as a result, its increase or decrease, which eventually leads to high-risk sexual behaviors (56). Also, this fact should be considered that the types of drugs and their use have different effects on the incline or decline of sexual desire in different people. For example, it is shown that the consumption of amphetamines increases sexual desire and this increase is associated with a feeling of coercion and unusual sexual behaviors. All of three types of high risk-sex behaviors, addiction, and aggression are linked and affect one another in a triangular process. When the triangular relationship of these behaviors is accepted; it could be accepted that all of them have a common origin. Stress may contribute as the main source of all of these three themes (57). In other words, high-risk sexual behavior, addiction, and aggression are all one social problem with different manifestations. In case of the presence of unresolved stress, especially traumatic type, there is an attitude to repression and forgetfulness (mostly in association with drug overdose), increased violence against the community (expression of aggression), and inclination toward revenge (high-risk sexual behavior) (58). Also, these 3 behaviors could convert to each other and when people tend to one of them, it is possible to tend to others during the time. Therefore, after years, the person expresses all of them. In other words, if 1 of these behaviors does not play its role as a stress reducer, the two others will engage (13). For instance, addiction - as one of these behaviors - could summon the two others and terminate aggression/high-risk sexual behavior as a result of drug withdrawal or drug influence. As mentioned previously, a triangular relationship between high-risk sexual behavior, addiction, and aggression could be observed. Based on this concept, when the two parts of the triangle come together, the third part withdraws and is impaired. Therefore, in community-based interventions, when one of them is cured, the other two are strengthened; and accordingly, interfering with one part is never complete (59). Each part of a triangle can be used against the other, because the inner turmoil of a system can be beneficial to the entire system $(59,60)$. High-risk sexual behavior, addiction, and aggression have a hierarchy. It is probable that one of them is more basic than the other two. Aggression is probably the axis for the other two. And it is also probable that in the process of their sustainability, this center would change and in the next steps, each component of 
high-risk sexual behavior and addiction will also play the role as an axis or a center (61). In this case, intervention and treatment in both the individual and the community domains are different. In the individual domain, the treatment includes, but is not limited to, emotional control, dealing with traumatic stress, and psychological and family therapy to treat addiction, and high-risk sexual behaviors. This systematic viewpoint helps social interventionists to consider all of these 3 aspects as a whole, when dealing with each of the high-risk sexual behavior, addiction, and aggression. As noted, treating just one of these complications may contribute in exacerbation of the other two $(13,54)$. The community domain based interventions -when dealing with high-risk sexual behavior, addiction, and aggression- are usually presented by separate social institutions, especially in the developing countries that do not have integrated approaches. This may lead to neutralization of their efforts. Therefore, it is suggested that a systematic and integrative approach should be implemented by integrated social institutions. Supporting triangular relationships can establish systematic views and the rules of the systems in relation to three basic human behaviors, namely: high-risk sex, addiction, and aggression. The systems theory is a comprehensive and holistic theory. A system is an entity of interactive elements and this interaction, gives it a totality and a sense of completeness. In this proposition, the elements established dual or triple interaction. The main limitation of this review article was the difference of definitions of sexual relations between societies (which sexual relations are deemed high risk) and translation of these into one scientific word. Another limitation of this study was the limited number of studies that examined all three variables. As a limitation, various intrapsychic factors determine human behavior, the current study exclusively focused on intrapsychic processes and its dynamism.

\section{Conclusions}

Proposing the triangle hypothesis of sexual relations, addiction, and aggression, led to defining the hypothetical triangular relationships between variables from the reviewed studies, and also, it led to defining the assumed relations, which were double and triple relationships, based on literature review, and the analysis confirmed them. Proving this triangular relationship, may increase the importance and the need to deal with and prevent any of these social issues; it can be expected that the other two variables are also controlled or reduced in line with the first one.

\section{Acknowledgments:}

We hereby thank all people who contributed in this research.

\section{Conflict of Interest:}

There is no conflict of interest to be declared.

\section{Authors' contributions:}

All authors contributed to this project and article equally. All authors read and approved the final manuscript.

\section{References:}

1) Hallfors DD, Waller MW, Ford CA, Halpern CT, Brodish PH, Iritani B. Adolescent depression and suicide risk: association with sex and drug behavior. Am J Prev Med. 2004; 27(3): 224-31. doi: 10.1016/j.amepre.2004.06.001. PMID: 15450635.

2) Madu SN, Matla MQ. Illicit drug use, cigarette smoking and alcohol drinking behavior among a sample of high school adolescents in the Pietersburg area of the Northern Province, South Africa. J Adolesc. 2003; 26(1): 121-36. doi: 10.1016/S0140-1971(02)00120-3. PMID: 12550825.

3) Kodjo CM, Auinger P, Ryan SA. Prevalence of, and factors associated with, adolescent physical fighting while under the influence of alcohol or drugs. J Adolesc Health. 2004; 35(4): 346.e11-6. PMID: 15830460.

4) Stueve A, O'Donnell LN. Early Alcohol Initiation and Subsequent Sexual and Alcohol Risk Behaviors Among Urban Youths. Am J Public Health. 2005; 95(5): 887-93. doi: 10.2105/AJPH.2003.026567. PMID: 15855470, PMCID: PMC1449273.

5) Molitor F, Truax SR, Ruiz JD, Sun RK. Association of methamphetamine use during sex with risky sexual behaviors and HIV infection among non-injection drug users. West J Med. 1998; 168(2): 93. PMID: 9499742, PMCID: PMC1304836.

6) Biglan A, Metzler CW, Wirt R, Ary D, Noell J, Ochs L, et al. Social and behavioral factors associated with high-risk sexual behavior among adolescents. J Behav Med. 1990; 13(3): 245-61. doi: 10.1007/BF00846833. PMID: 2213868.

7) Gilchrist H, Smith K, Magee CA, Jones S. A hangover and a one-night stand: Alcohol and risky sexual behaviour among female students at an Australian University. 2012. 
8) Rusch M, Lampinen TM, Schilder A, Hogg RS. Unprotected anal intercourse associated with recreational drug use among young men who have sex with men depends on partner type and intercourse role. Sex Transm Dis. 2004; 31(8): 492-8. doi: 10.1097/01.olq.0000135991.21755.18. PMID: 15273583.

9) Perry JL, Carroll ME. The role of impulsive behavior in drug abuse. Psychopharmacology. 2008; 200(1): 1 26. doi: 10.1007/s00213-008-1173-0. PMID: 18600315.

10) Charnigo R, Noar SM, Garnett C, Crosby R, Palmgreen P, Zimmerman RS. Sensation seeking and impulsivity: combined associations with risky sexual behavior in a large sample of young adults. J Sex Res. 2013; 50(5): 480-8. doi: 10.1080/00224499.2011.652264. PMID: 22456443, PMCID: PMC4520301.

11) Mustanski B, Newcomb ME, Clerkin EM. Relationship characteristics and sexual risk-taking in young men who have sex with men. Health Psychol. 2011; 30(5): 597. doi: 10.1037/a0023858. PMID: 21604883, PMCID: PMC3184611.

12) Siever LJ. Neurobiology of aggression and violence. Am J Psychiatry. 2008; 165(4): 429-42. doi: 10.1176/appi.ajp.2008.07111774. PMID: 18346997, PMCID: PMC4176893.

13) Morgan O. Addiction and spirituality: A multidisciplinary approach. Saint Louis, Missouri: Chalice Press; 2012.

14) Koob GF, Buck CL, Cohen A, Edwards S, Park PE, Schlosburg JE, et al. Addiction as a stress surfeit disorder. Neuropharmacology. 2014; 76: 370-82. doi: 10.1016/j.neuropharm.2013.05.024P. PMID: 23747571, PMCID: PMC3830720.

15) Zeinali A. Risk and Protective Factors in West Azerbaijan Province Students Addiction Susceptibility. Iraninan Psychiatry and Clinical Psychology. 2014; 20(1): 63-73.

16) Assari S, Moghani Lankarani M, Dejman M, Farnia M, Alasvand R, Sehat M, et al. Drug Use among Iranian Drivers Involved in Fatal Car Accidents. Front Psychiatry. 2014; 5: 69. doi: 10.3389/fpsyt.2014.00069. PMID: 25221521, PMCID: PMC4148638.

17) Ahmadi B, Alimohamadian M, Golestan B, Bagheri A, Shojaeezadeh D. Effects of domestic violence on the mental health of married women in Tehran. Journal of School of Public Health and Institute of Public Health Research. 2006; 4(2): 35-44.

18) Sulmasy DP. A biopsychosocial-spiritual model for the care of patients at the end of life. Gerontologist. 2002; 42(3): 24-33. doi: 10.1093/geront/42.suppl_3.24. PMID: 12415130.

19) Mirsoleimani L, Sanaee zaker B, Vaziri S, Lotfi F. The comparison of sexual behavior high risk sexual behaviour and self-harm behaviour in stimulants/narcotic substance abuse. Research on Addiction. 2011; 3(9): 150-67.

20) Zinat Motlagh F, Ahmadi Jouybari T, Jalilian F, Mirzaei Alavijeh M, Aghaei A, Karimzadeh Shirazi K. The Prevalence and Factors Associated with Aggression among Adolescences of Yasuj, Iran. J Health Syst Res. 2013; 9(3): 312-9.

21) Tucker JS, Wenzel SL, Elliott MN, Hambarsoomian K. Predictors of unprotected sex with non-cohabitating primary partners among sheltered and low-income housed women in Los Angeles County. J Health Psychol. 2006; 11(5): 697-710. doi: 10.1177/1359105306066625. PMID: 16908467.

22) Meyer JP, Springer SA, Altice FL. Substance abuse, violence, and HIV in women: a literature review of the syndemic. J Women's Health. 2011; 20(7): 991-1006. doi: 10.1089/jwh.2010.2328. PMID: 21668380, PMCID: PMC3130513.

23) Leigh BC, Stall R. Substance use and risky sexual behavior for exposure to HIV: Issues in methodology, interpretation, and prevention. Am Psychol. 1993; 48(10): 1035-45. doi: 10.1037/0003-066X.48.10.1035. PMID: 8256876, PMCID: PMC2585544.

24) Razzaghi E, Rahimi Movaghar A, Mohammad K, Mahdi H. A qualitative study of risky sexual behavior in injecting drug users in tehran. Journal of School of Public Health and Institute of Public Health Research. 2004; 2(2): 1-10.

25) Rehm J, Shield KD, Joharchi N, Shuper PA. Alcohol consumption and the intention to engage in unprotected sex: systematic review and meta - analysis of experimental studies. Addiction. 2012; 107(1): 51-9. doi: 10.1111/j.1360-0443.2011.03621.x. PMID: 22151318.

26) Kilpatrick DG, Acierno R, Saunders B, Resnick HS, Best CL, Schnurr PP. Risk factors for adolescent substance abuse and dependence: data from a national sample. J Consult Clin Psychol. 2000; 68(1): 19-30. doi: 10.1037/0022-006X.68.1.19. PMID: 10710837.

27) Tucker JS, Ryan GW, Golinelli D, Ewing B, Wenzel SL, Kennedy DP, et al. Substance use and other risk factors for unprotected sex: results from an event-based study of homeless youth. AIDS Behav. 2012; 16(6): 1699-707. doi: 10.1007/s10461-011-0017-9. PMID: 21932093, PMCID: PMC3244544. 
28) Kiene SM, Subramanian S. Event-level association between alcohol use and unprotected sex during last sex: evidence from population-based surveys in sub-Saharan Africa. BMC public health. 2013; 13(1): 583. doi: 10.1186/1471-2458-13-583. PMID: 23767763, PMCID: PMC3686662.

29) Purdie MP, Norris J, Davis KC, Zawacki T, Morrison DM, George WH, et al. The effects of acute alcohol intoxication, partner risk level, and general intention to have unprotected sex on women's sexual decision making with a new partner. Exp Clin Psychopharmacol. 2011; 19(5): 378-88. doi: 10.1037/a0024792. PMID: 21859223, PMCID: PMC3532854.

30) Colfax G, Vittinghoff E, Husnik MJ, McKirnan D, Buchbinder S, Koblin B, et al. Substance use and sexual risk: a participant-and episode-level analysis among a cohort of men who have sex with men. Am J Epidemiol. 2004; 159(10): 1002-12. doi: 10.1093/aje/kwh135. PMID: 15128613.

31) Purcell DW, Parsons JT, Halkitis PN, Mizuno Y, Woods WJ. Substance use and sexual transmission risk behavior of HIV-positive men who have sex with men. J Subst Abuse. 2001; 13(1): 185-200. doi: 10.1016/S0899-3289(01)00072-4. PMID: 11547619.

32) Heath J, Lanoye A, Maisto SA. The role of alcohol and substance use in risky sexual behavior among older men who have sex with men: a review and critique of the current literature. AIDS Behav. 2012; 16(3): 57889. doi: 10.1007/s10461-011-9921-2. PMID: 21390534, PMCID: PMC3743230.

33) Assari S, Yarmohamadivasel M, Lankarani MM, Sehat M, Narenjiha H, Rafiey H, et al. Having multiple sexual partners among Iranian intra-venous drug users. Front Psychiatry. 2014; 5: 125. doi: 10.3389/fpsyt.2014.00125. PMID: 25346698, PMCID: PMC4193211.

34) Mirabi P, Vasel MY, Moazen B, Sehat M, Rezazadeh M, Ahmadi K. Unprotected anal intercourse among Iranian intra-venous drug users. Frontiers in Public Health. 2013; 1: 1-6. doi: 10.3389/fpubh.2013.00034. PMID: 24350203, PMCID: PMC3859981.

35) Gyarmathy VA, Li N, Tobin KE, Hoffman IF, Sokolov N, Levchenko J, et al. Unprotected sex in heterosexual partnerships of injecting drug users in St. Petersburg, Russia. AIDS Behav. 2011; 15(1): 5864. doi: 10.1007/s10461-010-9721-0. PMID: 20532604, PMCID: PMC3048022.

36) Karimi M, Ghaheri H, Assari S, Ahmadi K, Moghani Lankarani M, Moghani Lankarani R, et al. Drug Injection to Sites other than Arm: A Study of Iranian Heroin Injectors. Front Psychiatry. 2014; 5: 23. doi: 10.3389/fpsyt.2014.00023. PMID: 24778621, PMCID: PMC3985009.

37) Saberian M, Atash Nafas E, Behnam B. Prevalence of domestic violence in women referred to the heath care centers in Semnan (2003). koomesh. 2005; 6(2): 115-22.

38) Derakhshanpour F, Mahboobi HR, Keshavarzi S. Prevalence of domestic violence against women. Journal of Gorgan University of Medical Sciences. 2014; 16(1): 126-31.

39) Balali Meybodi F, Hassani M. Prevalence of Violence Against Women by their Partners in Kerman. Iranian Journal of Psychiatry and Clinical Psychology. 2009; 15(3): 300-7.

40) Fazel S, Långström N, Hjern A, Grann M, Lichtenstein P. Schizophrenia, substance abuse, and violent crime. JAMA. 2009; 301(19): 2016-23. doi: 10.1001/jama.2009.675. PMID: 19454640, PMCID: PMC4905518.

41) Tatari F, Mousavi SA, Rezaei M, Khoshbakht E. The relationship between aggression rates and drugs abuse among posttraumatic stress disorder patients. Journal of Kermanshah University of Medical Sciences. 2013; 17(8): 521-39.

42) Abbey A. Alcohol's role in sexual violence perpetration: Theoretical explanations, existing evidence and future directions. Drug alcohol rev. 2011; 30(5): 481-9. doi: 10.1111/j.1465-3362.2011.00296.x. PMID: 21896070, PMCID: PMC3177166.

43) Kilpatrick DG, Ruggiero KJ, Acierno R, Saunders BE, Resnick HS, Best CL. Violence and risk of PTSD, major depression, substance abuse/dependence, and comorbidity: results from the National Survey of Adolescents. J Consult Clin Psychol. 2003; 71(4): 692. doi: 10.1037/0022-006X.71.4.692. PMID: 12924674.

44) Davis KC. The influence of alcohol expectancies and intoxication on men's aggressive unprotected sexual intentions. Exp Clin Psychopharmacol. 2010; 18(5): 418. doi: 10.1037/a0020510. PMID: 20939645, PMCID: PMC3000798.

45) Garrison CZ, McKeown RE, Valois RF, Vincent ML. Aggression, substance use, and suicidal behaviors in high school students. Am J Public Health. 1993; 83(2): 179-84. doi: 10.2105/AJPH.83.2.179. PMID: 8427319, PMCID: PMC1694564.

46) Liebschutz J, Savetsky JB, Saitz R, Horton NJ, Lloyd-Travaglini C, Samet JH. The relationship between sexual and physical abuse and substance abuse consequences. J Subst Abuse Treat. 2002; 22(3): 121-8. doi: 10.1016/S0740-5472(02)00220-9. PMID: 12039614, PMCID: PMC4861063. 
47) Epstein JA BG, Diaza T, Williamsa C, Griffina K. Aggression. Victimization and Problem Behavior Among Inner-City Minority Adolescents. Journal of Child \& Adolescent Substance Abuse. 2000; 9(3): 51 66. doi: 10.1300/J029v09n03 04 .

48) Davis KC, Logan-Greene P. Young Men's Aggressive Tactics to Avoid Condom Use: A Test of a Theoretical Model. Soc Work Res. 2012; 36(3): 223-31. doi: 10.1093/swr/svs027. PMID: 23139623, PMCID: PMC3490635.

49) Bayrami M, Esmaili A, Vahedi H. The Comparison of Factors and Personality Trait in High Risk Sexual and Normal Persons. Medical Journal of Tabriz University of Medical Sciences. 2010; 32(3): 13-7.

50) Abdi S, Abdollahi R, Babapoor J, Ghojazadeh M. The Comparison of Personality Traits Related To Behavioral Inhibition/Activation Brain Systems in the People with High Risk, Low Risk Sexual Relationships and Normal People. Medical Journal of Tabriz University of Medical Sciences. 2009; 31(3): 49-56.

51) Lescano CM, Hadley WS, Beausoleil NI, Brown LK, D'eramo D, Zimskind A. A brief screening measure of adolescent risk behavior. Child Psychiatry Hum Dev. 2007; 37(4): 325-36. doi: 10.1007/s10578-0060037-2. PMID: 17109222.

52) Malamuth NM, Addison T, Koss M. Pornography and sexual aggression: Are there reliable effects and can we understand them? Annu Rev Sex Res. 2000; 11(1): 26-91. PMID: 11351835.

53) Rezazade M, Lashani Z, Ahmadi K. Mental Health Status Among the Staff of Harm Reduction Centers. Int J High Risk Behav Addict. 2014; 3(1): e12244. doi: 10.5812/ijhrba.12244. PMID: 24971296, PMCID: PMC4070187.

54) Illangasekare SL, Burke JG, Chander G, Gielen AC. Depression and social support among women living with the substance abuse, violence, and hiv/aids syndemic: a qualitative exploration. Women's health issues. 2014; 24(5): 551-7. doi: 10.1016/j.whi.2014.05.004. PMID: 25213747, PMCID: PMC4163008.

55) Titelman P. Triangles: Bowen family systems theory perspectives. Routledge; 2012.

56) Vaziri S, Lotfi Kashani F. Effect of Methamphetamine and narcoric on the increase of libido and reckless sexual behavior. Andishe va Raftar. 2010; 4(15): 81-91.

57) Samadypoor R, Tamini BK. The Role of Personality Pattern Behaviors in Risk Behaviors of High School Students. International Journal of High Risk Behaviors and Addiction. 2016; 5(4): e36313. doi: 10.5812/ijhrba.36313.

58) James R, Gilliland B. Crisis intervention strategies. Nelson Education; 2012.

59) Burns BJ, Schoenwald SK, Burchard JD, Faw L, Santos AB. Comprehensive Community-Based Interventions for Youth with Severe Emotional Disorders: Multisystemic Therapy and the Wraparound Process. Journal of Child and Family Studies. 2000; 9(3): 283-314. doi: 10.1023/A:1026440406435.

60) McLeroy KR, Norton BL, Kegler MC, Burdine JN, Sumaya CV. Community-Based Interventions. Am J Public Health. 2003; 93(4): 529-33. doi: 10.2105/AJPH.93.4.529. PMID: 12660190 PMCID: PMC1447783.

61) Najafi M, Soleimani AA, Ahmadi K, Javidi N, Kamkar EH. The Effectiveness of Emotionally Focused Therapy on Enhancing Marital Adjustment and Quality of Life among Infertile Couples with Marital Conflicts. Int J Fertil Steril. 2015; 9(2): 238-46. PMID: 26246883, PMCID: PMC4518493.

62) Booth RE, Watters JK, Chitwood DD. HIV risk-related sex behaviors among injection drug users, crack smokers, and injection drug users who smoke crack. Am J Public Health. 1993; 83(8): 1144-8. doi: 10.2105/AJPH.83.8.1144. PMID: 8342724, PMCID: PMC1695160.

63) Hassannejad R, Kassaian N, Ataei B, Adibi P. High risky behaviors among intravenous drug users in Isfahan, Iran: A study for hepatitis C harm reduction programs. Int J Prev Med. 2012; 3(Suppl1): S73-8. PMID: 22826773, PMCID: PMC3399296.

64) Ahmadi K, Rezazade M, Nafarie M, Moazen B, Yarmohmmadi Vasel M, Assari S. Unprotected sex with injecting drug users among Iranian female sex workers: unhide HIV risk study. AIDS Res Treat. 2012; 2012: 651070. doi: 10.1155/2012/651070P. PMID: 22506107. 